\title{
Interacción e interactividad: Manual de museografia interactiva
}

\author{
Manuel Gándara Vázquez
}

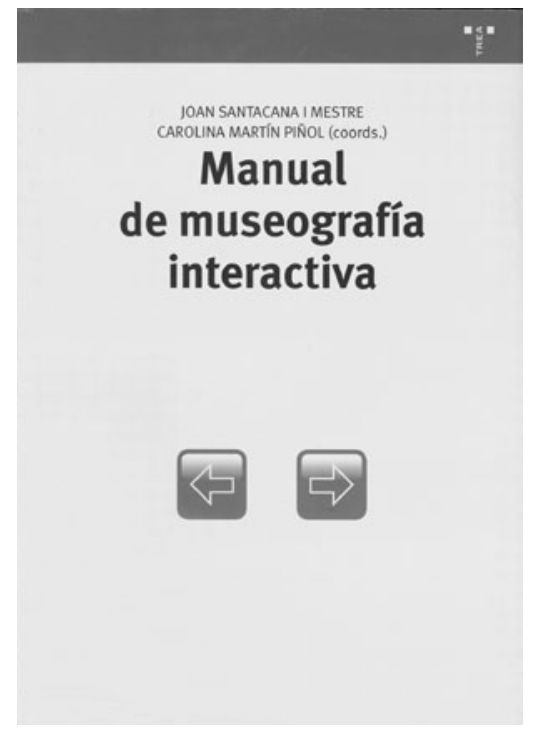

FIGURA 1. Portada de Manual de Museografía Interactiva, Joan Santacana I Mestre y Carolina Martín Piñol, TREA, 2010.
S i Cataluña es particularmente prolífica en sus contribuciones a la museología contemporánea, Joan Santacana i Mestre, uno de los coordinadores del texto que aquí nos ocupa, Manual de museografía interactiva (Santacana y Martín 2010a), es uno de los autores responsables de esa alta productividad: tan sólo en los últimos 10 años ha escrito o coordinado más de 10 libros sobre teoría y educación en materia museológica (Hernández y Santacana 2006; Santacana 2009; Santacana y Llonch 2012; Santacana y Masriera 2012). Estar al día con este autor y sus colaboradores requeriría invertir varios meses de trabajo.

Así, sin pretender un conocimiento exhaustivo de este cuerpo bibliográfico, me atrevo a comentar el citado Manual. En su presentación, los coordinadores señalan que las tecnologías de la información y la comunicación (TIC) han llegado al museo para quedarse, e incluso en las instituciones más reticentes a su utilización - los museos de arte - tienen ya un considerable impacto. Es por ello oportuno, argumentan, contar con un manual que aborde específicamente este tema. Y tienen razón, amén de que el centro de las disertaciones no es la tecnología en sí, sino la manera en que ésta permite hacer del museo un espacio más horizontal: un lugar de diálogo que abre nuevas oportunidades para la participación del público.

En realidad ya existían algunas publicaciones al respecto, ${ }^{1}$ pero ninguna con la ambición y exhaustividad con la que nos regalan ahora Santacana y su equipo: un libro que es el resultado, nos informan, de la experiencia ganada en un curso de maestría en línea sobre museografía impartido desde la Universidad de Barcelona (Santacana y Martín 2010b:18).

Se trata de un volumen compuesto por 12 capítulos (cuyo número citaré entre paréntesis), a los que se suman una introducción y un epílogo escritos por el propio Santacana. Sus dimensiones corresponden con la ambición del proyecto: 655 páginas con numerosas ilustraciones, muchas en color, casi un tercio de las cuales están en el capítulo 2: "Análisis y clasificación de los medios interactivos", de Carolina Martín Piñol y Júlia Castell Villanueva, al que regresaré en seguida.

\footnotetext{
${ }^{1}$ Una bibliografía parcial aparece en Gándara (2001).
} 
En la "Introducción: La museografía y la revolución didáctica", Santacana y Martín introducen dos de las nociones esenciales del libro: interacción e interactividad, que relacionan tanto con los avances en la pedagogía como con el contexto social y cultural creado por las nuevas tecnologías digitales; es inevitable, sostienen con acierto, que los museos que han tenido un acercamiento inicial tibio reconozcan en las nuevas tecnologías una oportunidad para generar experiencias y aprendizajes más significativos. Este argumento se desarrolla a detalle en el capítulo 1, "Introducción al análisis de modelos de museografía interactiva", en el que Santacana liga la interactividad a aquellas características de nuestro aparato cognitivo que hacen que estos nuevos recursos sean eficaces para promover el aprendizaje; en efecto, la incorporación de elementos lúdicos y emocionales los dota de un poder pedagógico adicional. De forma notable, esta contribución también caracteriza y categoriza los tipos de interactividad, con las dificultades que implica esta empresa.

Tras la definición de la interactividad como "la capacidad del receptor para controlar un mensaje no lineal hasta el grado establecido por el emisor, dentro de los límites del medio de comunicación asincrónico" (Santacana y Martín 2010b:20), Santacana (2010:30) también propone una clasificación tripartita: la interactividad de carácter informático, la de carácter mecánico o manipulativo y la de carácter humano.

Como ya se ha mencionado, el capítulo 2 aplica esta clasificación combinándola con los diferentes tipos de medios y con los sentidos involucrados en cada caso, lo que resulta en una útil matriz con 120 diferentes tipos o categorías (Martín y Castell 2010:110-111). Las autoras documentan cuando menos un ejemplo para cada categoría, consignando el tipo de medio interactivo en cuestión (incluido su emplazamiento, costo y tiempo de uso) y el segmento de público al que éste está destinado. También ofrecen una fotografía de un caso real - la mayoría proveniente de museos europeosque ilustra su operación. Así, el lector cuenta con un medio de consulta efectivo sobre módulos que involucran, por ejemplo, el sentido del olfato, los que cuentan con un dispositivo táctil o bien aquellos basados en experiencias sensoriales mecánicogustativas. Este análisis, que es muy meritorio — dado que constituye una especie de mapa general que permite entonces caracterizar, en principio, cualquier dispositivo interactivo-, es una de las contribuciones centrales del volumen. Esto, por supuesto, sin demérito del resto de los capítulos, todos ellos bien escritos, documentados y argumentados, que abordan otras temáticas de la interactividad.

Los capítulos 3 (escrito por Magali Lladó Morales y Javiera Atenas), y 4 (por María Pilar Rivero Gracia), versan sobre los recursos en línea -en particular, con las opciones que la Web 2.0 ofrece para que los usuarios contribuyan en contenidos o se enlacen en redes sociales-, de su impacto para una cibermuseología, respectivamente. Maria Feliu y Clara Masriera, en "Interactividad y mediación humanas" (5), se enfocan en la interacción facilitada por humanos, es decir, lo que se conoce como interpretación personalizada o mediación, donde se incluyen casos de interpretación dramatizada o caracterizada, y estudian un par de ejemplos importantes. Por su parte, "Recursos y materiales didácticos interactivos" (6) analiza aquellos que permiten extender la experiencia del museo hacia contextos escolares; sus autores, Laia Coma y Neus Sallés, proponen una metodología para su diseño y desarrollo que seguro será útil para quienes quieran explorar esta variante de los recursos interactivos. El capítulo 7 aborda la relación entre turismo e interactividad, aunque su autora, Nayra Llonch Molina, se centra más en el papel del turismo cultural y su efecto en museos y sitios, es decir, en interacciones humanas, que en la tecnología.
Los siguientes tres capítulos abordan el problema de la interactividad en distintos tipos de museos. En "La interactividad social de los museos" (8), Ramón Sala narra las resistencias de los grandes museos nacionales europeos a la incorporación de recursos interactivos y, a la par, examina, con varios ejemplos, los intentos de instituciones museísticas del Viejo Continente por adoptarlos y modernizar su discurso, un ejercicio que sería útil reproducir para el contexto latinoamericano. Andreu Besolí Martín, en "Interactividad y comunicación museográfica audiovisual en exposiciones de arqueología e historia" (9), plantea con acierto los retos que presenta este tipo de recintos y cómo la interactividad añade una nueva dimensión para mejorar su eficacia. En adición, Victoria López Benito aborda "Las posibilidades de la museografía interactiva en los museos de arte" (10), un texto que de manera convincente demuestra no sólo que la interactividad aporta a la comprensión y disfrute del arte tradicional, sino que hay nuevas formas de arte interactivas, por lo que, coincidiendo con esta autora, es previsible que la tendencia hacia la interactividad se generalizará en este tipo de museos.

Los siguientes dos capítulos regresan a cuestiones de orden más general: F. Xavier Hernández Cardona, Tania Martínez Gil y Ma. del Carmen Rojo Ariza discuten "Los límites de la interactividad" (11), en el que analizan las desventajas, o los "contras", de la interactividad, con lo que se balancea el volumen, que en general subraya los "pros", y se concluye que, a pesar de las limitaciones (que van desde el costo y la obsolescencia hasta los efectos que tienen en la experiencia de visita), será imposible prescindir de la interactividad en un mundo que demanda museos mucho más dialogantes y menos verticales. En "Evaluar la interactividad" (12), Ferran Urgell i Plaza y Cristina Pou hacen una excelente síntesis de los orígenes y desarrollo de los estudios de públicos — de hecho, este 
capítulo constituye una muy buena introducción y estado del arte para quien quiera iniciarse en el tema-, aunque en realidad poco abundan sobre la propia evaluación de la interactividad como tal. De hecho, uno de los asuntos que, en general, está poco representado en el libro es el de la usabilidad: es decir, qué tan fácil de aprender, qué tan memorable, qué tan eficaz es la tecnología, y hasta dónde su diseño evita o favorece que el usuario cometa errores $y$, al final del uso, quede con una sensación subjetiva favorable (en torno del concepto técnico de usabilidad, véase Nielsen 2000). Claramente, en un contexto como el museo, en que el visitante con dificultad dedicará mucho tiempo a aprender a usar un interactivo, la usabilidad es clave, como ya se ha argumentado en detalle en otro lado (Gándara 2001).

Cierran el libro, a manera de epílogo, unas "Reflexiones finales en torno a la interactividad: El futuro ha comenzado", del propio Santacana, quien ve en la interactividad ( $y$ sus diferentes variantes) una manera de lograr que el museo sea más incluyente, más dialogante, menos vertical y más participativo. Ésta es, por supuesto, una noble meta, que compartimos. Pero, por lo mismo, cabe reflexionar sobre el concepto de interactividad que sostiene el libro: ${ }^{2}$ si un cartel impreso puede considerarse interactivo por razón de que des-

\footnotetext{
${ }^{2}$ Aunque por las limitaciones e intención de esta reseña no es posible discutir con profundidad este asunto central, se aborda en extenso en un texto que en breve será publicado (Gándara en prensa).
}

pierta una reflexión en el visitante (Santacana 2010:62), entonces prácticamente cualquier recurso museográfico lo es, y cualquier museo cumpliría con la definición, dejando a las tecnologías digitales, centro original de la propuesta, un papel menos protagónico.

Algo similar sucede con la interactividad humana, que quizá podría diferenciarse de la digital, y llamarle interacción, porque, de otra manera, cualquier parque nacional que use intérpretes habría sido desde siempre interactivo. Un punto más, también importante, que podría discutirse en otro ámbito, sería la medida en que los medios digitales (para los que por norma reservamos el apelativo de interactivos) son en realidad más horizontales; sin duda, permiten una comunicación de dos vías, pero no por ello son simétricos: el lenguaje del museo se plasma, finalmente, en la propia exposición; el público no "habla" en ese lenguaje, aunque las redes sociales abran ahora un canal de retroalimentación.

Sin embargo, el que existan estos puntos por discutir no demerita en absoluto la importancia ni la magnitud de la contribución de Santacana y sus colaboradores. Este libro es una muy bienvenida adición a la literatura museológica: Ilena un hueco importante de manera inteligente, creativa y exhaustiva.

\section{Referencias}

\section{Gándara Vázquez, Manuel}

2001 "Aspectos sociales de la interfaz con el usuario: una aplicación en museos", tesis de Doctorado en Diseño y
Nuevas Tecnologías, México, UAM-A. En prensa "Interacción e interactividad: Hacia una conversación con los visitantes a museos y sitios patrimoniales", en José García Targa (ed.), Museums and Heritage Spaces at Mexico: Who do we Explain/explicate the Heritage?, Londres, BAR.

Hernández Cardona, Francesc Xavier y Joan Santacana i Mestre

2006 Museología crítica, Gijón, Trea.

Martín Piñol, Carolina y Julia Castell Vi-

Ilanueva

2010 "Análisis y clasificación de los modelos interactivos", en Joan Santacana i Mestre y Carolina Martín Piñol 2010a:87-333.

Nielsen, Jakob

2000 Designing Web Usability, Indianápolis, New Riders.

Santacana i Mestre, Joan 2009 Museografías emergentes, Gijón, Trea.

2010 "Introducción al análisis de modelos de museografía interactiva", en Joan Santacana i Mestre y Carolina Martín Piñol 2010a:25-86.

Santacana i Mestre, Joan y Nayra Llonch Molina

2012 Manual de didáctica del objeto en el museo, Gijón, Trea.

Santacana i Mestre, Joan y Carolina Martín Piñol (eds.)

2010a Manual de museografía interactiva, Gijón, Trea.

2010b "Introducción: La museografía y la revolución didáctica", en Joan Santacana i Mestre y Carolina Martín Piñol 2010a:15-24.

Santacana i Mestre, Joan y Clara Masriera Esquerra

2012 La arqueología reconstructiva y el factor didáctico, Gijón, Trea.
Título en inglés: Interaction and interactivity: Manual de museografía interactiva 